Fecha de recepción: mayo 2021 Fecha de aceptación: junio 2021 Versión final: julio 2021

\section{Virtualidad, Ecosistemas cognitivos, Tendencias y Comportamientos en ambientes post-digitales. Aportes a la construcción de un encuadre conceptual}

Diana Rodríguez Barros ${ }^{(1)}$

\begin{abstract}
Resumen: En los procesos de la virtualidad se reconocen cambios tecnológicos y conectividad omnipresente a Internet, que influyen los modos de precisar relaciones personales, sociales, profesionales y académicas. Interesa analizar cuestiones centrales, a manera de meta-transformaciones formalizadas en acciones, que se mantienen en vigencia profundizando validez en los escenarios actuales pandemia COVID-19. Es intención aportar a la construcción de un encuadre conceptual sobre virtualidad, ecosistemas cognitivos, tendencias y comportamientos en ambientes post-digitales vinculados a prácticas didácticas en ambientes proyectuales.
\end{abstract}

Palabras clave: Virtualidad - Post-digital - Prácticas didácticas - Diseño - Competencias híbridas

[Resúmenes en inglés y portugués en la página52]

(1) Arquitecta UNMdP. Dra. Arquitectura UBA. Facultad de Arquitectura, Urbanismo y Diseño. Universidad Nacional de Mar del Plata. Profesora Titular Regular

\title{
Introducción
}

En los procesos de la virtualidad, se reconocen por un lado, los cambios tecnológicos vinculados a soportes físicos, soportes lógicos y conectividad a la red Internet, que influyen y han alterado modalidades de precisar relaciones personales, sociales, profesionales y académicas. Por otro lado, las alteraciones profundas del estado de los hechos o de las cosas, así como el modo en que se plantea la relación con el mundo y las acciones devenidas. Interesa analizar una serie de cuestiones centrales, a manera de supuestos formalizados en acciones, que fueron precisadas por Kevin Kelly (2016) en etapa pre-pandémica y luego replicadas por Pardo Kuklinski (2016). Mantienen vigencia, profundizado y exacerbado su validez en estos escenarios actuales de pandemia COVID-19. 
Se enuncian como acciones singulares, valiosas e inmateriales que se despliegan en los entornos virtuales. Resultan tanto inevitables como complementarias y válidas. Es así que interesa partir de tales presupuesto, exponerlos y cotejarlos con las perspectivas de otros autores para confrontar o acordar con tales conceptos y de tal forma actualizar de estado de la cuestión que aporte a la construcción de encuadres conceptuales sobre el tema de la virtualidad y los ecosistemas cognitivos que tienen injerencia directa con prácticas didácticas en ambientes proyectuales.

Tales acciones presentan tendencias y formas particulares de comportamiento y actitudes. Pueden ser interpretadas como transformaciones sucedidas en la virtualidad. Será conveniente precisarlas como meta-tranformaciones subyacentes a partir de desarrollos de las intervenciones a que dan lugar. Estas descripciones se posicionan en posturas críticas desde miradas reflexivas. Proponen un primer acercamiento amplio a los entornos postdigitales, virtuales e interconectados a la Web, junto a las acciones sucedidas exacerbados por las condiciones actuales derivadas de la pandemia COVID-19.

En estas circunstancias, se vislumbra plantear nuevas normalidades. Posiblemente con más precisión se vislumbran nuevas habitualidades. En particular, el controvertido filósofo eslavo Slavoj Žižek (2020) afirma que no hay vuelta a la anterior normalidad y que es imperativo construir una nueva, original e inédita, pero que tenga lazos con los cimientos previos. Por eso interesa analizar y reflexionar sobre ciertos supuestos que pueden actuar como nexos en este tránsito para poder comenzar a discernir nuevas tendencias o tendencias reversionadas.

Pero, desde la especificidad disciplinar propia y sin perder la percepción de la complejidad de la situación, interesa enfocar tales tendencias y acciones desde la perspectiva proyectual. Al respecto, Brown (2016) define, encuadrado en la corriente metodológica y conceptual del Pensamiento de Diseño, una serie de espacios de intervenciones que atraviesan las distintas etapas de todo proceso proyectual. Son espacios organizados de forma no necesariamente lineal y cuentan con retroalimentación crítica. Tales espacios reconocen ambientes para Inspirar, Idear, Experimentar, Implementar y Prototipar. Al respecto identifica y legitima acciones creativas, co-creativas e innovadoras, en tanto innovación asumida como resultados de la concreción e implementación de conceptos creativos, según enfoques mono, inter y multidisciplinarios en ambientes de Diseño. Desde otra perspectiva Piscitelli y Alonso (2020), plantean un recorrido asimilable y que se pueden asociar a un proceso proyectual. Está traducido en acciones/verbos que remiten a Innovar, (In)Formar, Diseñar, (el buen) Trabajar. Desde ambos enfoques se despliegan trayectorias que reconocen complejidad e interacción en cada etapa sucedida.

Las acciones propuestas por Kevin (2016) pueden dar cuenta de un posible mapeo de acciones comunes, que son sucedidas y resignificadas en la virtualidad de manera singular y traducidas en competencias híbridas. La serie refiere a Volverse otra cosa, Devenirse (becoming); Fluir constante (flowing); Habitar pantallas (screening); Interacturar (interacting); Acceder (accesing); Filtrar (filtering); Rastrear (tracking); Remezclar (remixing); Compartir (sharing); Incorporar conocimiento con inteligencia artificial al diseño (cognifying); Preguntarse (questioning); Empezar, Recomenzar (beginning). 


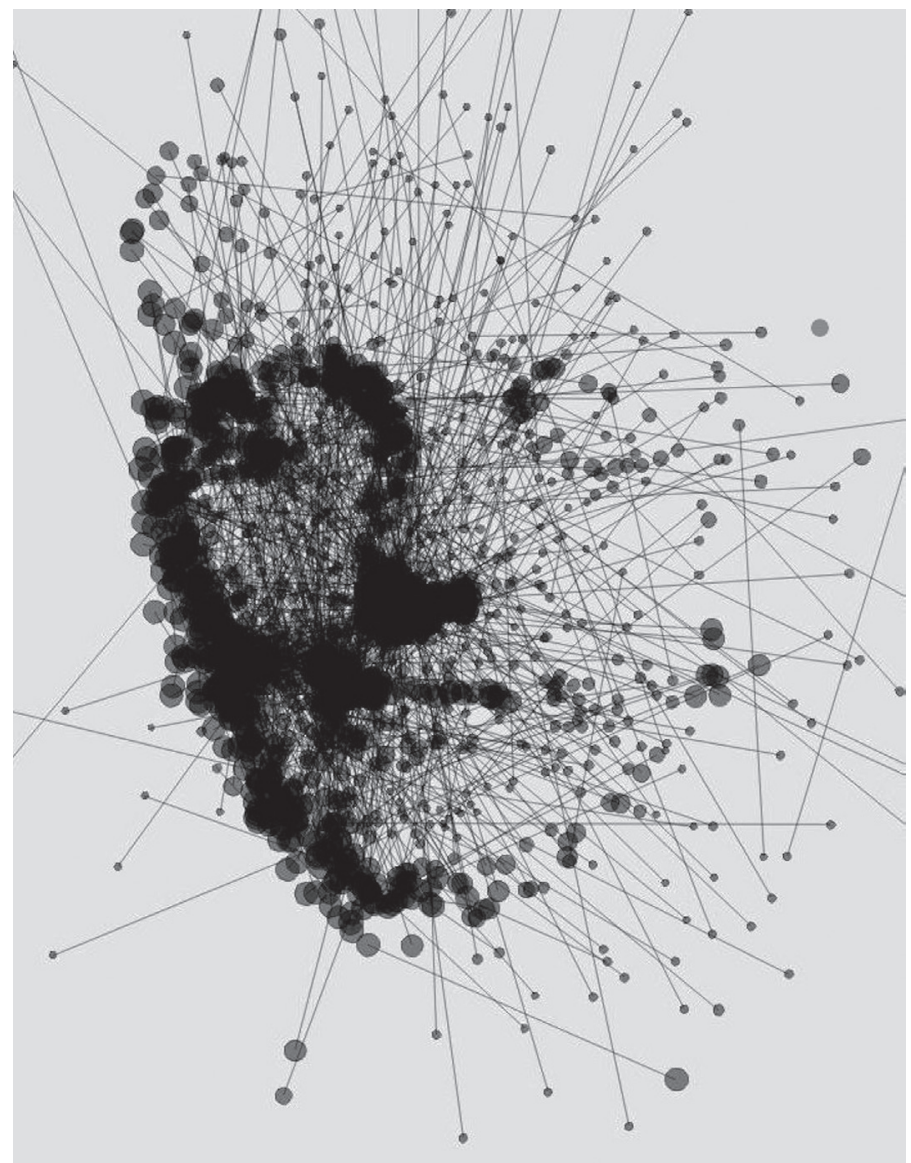

Figura 1. Unconnected. Albiac, Sergio. Recuperado https://tinyurl.com/yptaztcn

\section{Mapeo de acciones comunes en ambientes Post-Digitales Tendencias y comportamientos}

\section{Volverse otra cosa, Devenirse (Becoming)}

En los entornos postdigitales, Kelly (2016) sostiene que se recupera el estado de novato, que se superpone insoslayablemente a los estados previos de expertos disciplinares. Es permanente la necesidad de provocar la necesidad de generar deseos, expectativas y desafíos que afrontar. La exigencia para estar atentos y alertas se torna constante e inestable a las dinámicas sociales, académicas y profesionales. Más allá de naturalizar el uso de las 
tecnologías, no se pueden pensar independientes de la conectividad a la red, a un ritmo cada vez mayor y exacerbado a su máxima expresión durante este tiempo de aislamiento obligado. Se podría análogamente comparar las acciones de la vida contemporánea con la metáfora de las aplicaciones y programas en estado de permanente actualización. Tal situación de inestabilidad y vulnerabilidad impide, en consecuencia, planificar a largo plazo. Esta circunstancia se traduce en una permanencia variable, pero atrapada en un presente sin fin. O sea, la inevitabilidad de la incertidumbre y la variabilidad, como elemento de tracción constante. Estar anclados en el presente, sin una distancia generacional, pareciera que niega el futuro. $\mathrm{O}$ sea, se habita un inevitable y permanente presente sin fin. Desde posiciones críticas y antagónicas aunque complementarias, Harari (2018) aporta una perspectiva enfocada en la pérdida de credibilidad cuando las revoluciones paralelas devenidas de las tecnologías post-digitales proponen extremos retos a especie humana.

Por otro lado Krznaric (2020), indica que se vive en permanente "era de la tiranía del ahora", resultado en un "cortoplacismo frenético" agudizado por la crisis pandemia que se enfrenta. Es así que el filósofo australiano se redirecciona hacia los talentos exclusivamente humanos como medio de contrarrestar esta situación. Su propuesta de "pensamiento catedral" de lo que denomina como "rebeldes del tiempo" y de movimientos inspiradores en todo el mundo, indica la conveniencia de planificar proyectos que trascienden las generaciones inmediatas con la mirada hacia el futuro mediato y lejano.

\section{Fluir constante (Flowing)}

El concepto de fluidez ya fue desarrollado por Bauman $(2018,2006)$, desde la multiplicidad de modernidades líquidas. Sin embargo, se observa que sigue impregnando la realidad de la vida y los tiempos contemporáneos. Tal estado implica una dinámica direccionada hacia el cambio constante. Nada está clausurado o finalizado. Los procesos fluidos resultan más importantes que los productos. Esta circunstancia implica un proceso metódico de mutación y variaciones, así como mejoras que conceptualmente podrían superar en importancia a los productos resultantes.

Se caracteriza de manera fuerte en el paso del almacenamiento de lo físico y sólido de lo material, al fluir de lo inmaterial y evanescente de la digitalización en la virtualidad. En este estado de liquidez se reconoce la prevalencia de valores de inmediatez, personalización, interpretación, accesibilidad y aumento de la capacidad de descubrir (discoverability, serendipity). Para Kelly (2016) básicamente este accionar subyace con la cultura de los emprendedores y diseñadores. Es así que describe, en correspondencia, un pasaje que transita diferentes grados hasta llegar al actual estado de fuidez muy asimilable al encuadre que proponen las diferentes etapas del Pensamiento de Diseño. Primero, un estado fijo y solitario, instancia tradicional e inicial en correspondencia con el trabajo estable e inmodificable propio del artesano. Segundo, un estado ubicuo y gratuito, instancia en correspondencia con la primera etapa de creación basada en la replicación, la cultura de 
la reproducibilidad y la copia distribuida fácilmente. Tercero, un estado de movilidad y colaboración, en correspondencia con la segunda etapa de creación basada en plataformas, donde cada producto surge y se remezcla en la nube. Cuarto, un estado abierto y de cambio constante, en correspondencia con la tercera etapa de creación, que muta hacia la innovación en tanto se concreta la idea. Sucede, habitualmente en los entornos post-digitales, que la audiencia-usuario deviene en $\unrhd$ prosumidor $\bigotimes$ en tanto personaje copartícipe en la ideación, producción, uso y consumo. Frente a esta situación, se produce cada vez menor resistencia con relación a las prácticas académicas y profesionales en los diseñadores, resultado de las posibilidades de expansión, nuevas audiencias y nuevas gestiones que presionan para imponerse.

Para Piscitelli y Alonso (2020), la figura de "prosumidor" es equivalente y oportuna asociarla en la virtualidad con la figura de "conector", en la medida en que es el actor que genera y formaliza lazos entre la audiencia-usuario-consumidor.

\section{Habitar las pantallas (Screening)}

El texto impreso, para Kelly (2016), ha resultado históricamente estímulo para el cambio. Se ha sustentado en la estabilidad, la objetividad y el pensamiento lineal, así como ha sido validado por la ciencia, la prensa y la ley. En cambio, los habitantes contemporáneos de las pantallas pasan por alto la lógica clásica de los libros y el rechazo a la copia. De tal forma se despierta por un lado, niveles inquietantes de incertidumbre. Por otro, modos aún inciertos de validación del conocimiento, contraponiendose a la racionalidad científica y a la inmersión literaria tradicional.

Tal circunstancia coincide con lo que Piscitelli y Alonso (2020) definen como asimilable vuelta a la oralidad pre-gutenbergiana, donde el texto se reemplaza por la imagen a diferencia de la oralidad de la etapa pre-imprenta.

Al respecto, Pardo Kuklinky (2014), indica que el habitar las interfaces de las pantallas, estado ideal de los screenagers implica un razonar y pensar diferente. Estos personajes prefieren y optan por la multitarea, el procesamiento paralelo, la lectura de texto en forma no-lineal y secuencial, y en particular la predilección de imágenes por sobre palabras. El principio de autoridad y de verdad, no es propiedad exclusiva de los autores y autoridades sino del ensamblando y re-ensamblando en tiempo real realizado por la propia audiencia que le va otorgando validez. Los datos y la información están, por un lado, en las plataformas de los buscadores cada vez más omnipresentes, complejos y poderosos. Por otro, en la figura alegórica de la nube que los almacena y manipula. A pesar de la visibilidad extrema en las redes, no se confronta. Ante un error prevalece como idea que siempre se puede recomenzar de manera similar al reinicio propio del reseteo. 


\section{Interacturar (Interacting)}

El valor de la interacción radica en las posibilidades de relacionarse y accionar con las interfaces para garantizar el buen uso, compensar necesidades e intereses de usuarios y conseguir que éstos transformen sus intervenciones en algo simple, eficaz, productivo y satisfactorio. Según Kelly (2016), es prioritario el desarrollo de sistemas de tecnología complejos (programas, dispositivos móviles y otros dispositivos electrónicos) en ámbitos de intercambio, control y comunicación respondiendo a conductas racionales efectivas entre usuarios, equipos, programas y redes, sea tanto desde intervenciones individuales como colectivas. Entonces, una parte importante del futuro de la tecnología reside en descubrir nuevas interacciones, cada vez más antagónicamente tanto transparentes como oscuras.

Siang (2018), citando y retomando desarrollos validados de Crampton Smith (2008) y Silver (2010), reconoce cinco dimensiones para comprender lo que implica la interacción vinculada a la práctica de diseñar productos digitales, entornos, sistemas y servicios. Al respecto remite a palabras simples, representaciones visuales (imágenes, tipografía e íconos), objetos reales, tiempos de uso y naturalización de comportamientos. Consecuentemente, se destaca que cada vez de manera más proactiva tales dimensiones desarrollan formalizaciones vinculadas a modalidades de interacción con ejes corporales referidos a contraseña biométrica y sentidos humanos íntimos e inmersivos.

La consecuencia directa indica que un objeto que no interactúa se asume como deteriorado. Desde otra perspectiva se puede decir, según Harari (2018), que tales objetos sobre los que no se plantea algún tipo de relación, también pueden identificarse con categorías propias de los objetos estéticos y contemplativos del mundo artístico.

\section{Acceder (Accesing)}

La consecuencia inmediata de la fragilidad del estado de cambio permanente que se vivencia en los entornos post-digitales provoca que el poder sobre la propiedad pierda el carácter de centralidad imperante hasta el siglo pasado. De manera opuesta el poder muta en dirección al acceso a la actualización y al cambio. Para Kelly (2016) se trata de poner en valor la capacidad de utilizar algo, en lo posible personalizado y con rasgos de unicidad, cuando surge el deseo sin importar de quién es la propiedad.

Tal tendencia se caracteriza por una serie de rasgos. La desmaterialización, para producir con menos materiales; la demanda en tiempo real sostenida por redes inteligentes, para vincular información, inteligencia artificial y acción; la descentralización, para distribuir o dispersar funciones, poderes, personas o cosas fuera de la centralidad de una ubicación o autoridad, circunstancia en gran parte refutada por la realidad actual; las plataformas sinérgicas, para trabajar conjuntamente y de la misma manera y asimismo para conseguir un objetivo determinado; la nube, metáfora que describe un único ecosistema de repositorios inagotables conformados por redes mundiales de servidores virtuales remotos 
e interconectados, para almacenar y administrar datos, ejecutar aplicaciones o entregar contenido o servicios, así como para facilitar el acceso en línea desde cualquier dispositivo conectado a Internet.

Harari (2018) indica que, a modo de resistencia, tales tendencias refieren a la necesidad de valorar y acceder privilegiadamente a aquello que ostente carácter de unicidad, por lo tanto, mantenga el valor de la cualidad de lo que es único y exclusivo. Sin embargo, aunque se restrinja la posibilidad en aquello personalizado de ser accedido, copiado, almacenado o remezclado, tal condición es absoluta e inquietantemente lábil.

\section{Filtrar (Filtering)}

Ante el exceso de información lo que escasea es la atención. Posiciones de privilegio corresponden a quienes según roles diferenciados desde las redes así como con modos diversos, tanto directos o sutiles como individuales o colectivos, influyen y manipulan la atención al filtrar, seleccionar, direccionar y recomendar información.

Pariser (2012), ya había desarrollado el concepto de burbuja de filtrado (overfitting), posibilidad implícita desde siempre en la estructura de cada plataforma. Aunque con grados de supuesta anarquía, siempre hay subyacente un invisible orden inicial ideado por sus creadores. Se expresa por algoritmos de búsquedas personalizadas que reducen y re-direccionan la complejidad de ideas y acciones de los resultado en las búsquedas.

Kelly (2016) reconoce el rol de los influenciadores (influencers) que corresponden a individuos que surgen naturalmente desde intereses personales, generalmente sin proponérselo, tendencia cada vez más fuerte. Detentan una de las aptitudes más valoradas en la era de la información. Son capaces de filtrar y depurar información; deciden lo que vale la pena conocer y lo que no; contagian curiosidad, entusiasmo y orientan gustos; consiguen viralizar contenidos, es decir, multiplicar la difusión y la propagación de distintos tipos de información (videos, imágenes, etc.); gozan de niveles altos de credibilidad sobre temas concretos y tienen considerable número de seguidores sobre los que inciden en sus decisiones. Son así consagrados como prescriptores, desde condiciones muy lábiles de validación, cuya presencia y opiniones actúan en las redes sociales marcando tendencias y pautas de consumo, con inusitado nivel de seguimiento y resultados altamente monetizables. Sin embargo, hay jerarquías distintas que indican diversos grados de influencia, alcance y permanencia. Existen personajes que actúan como curadores validados y no necesariamente interactúan con numerosos grupos de seguidores en las redes. Son aquellos que son influencias sólidas y actúan sobre pocas personas, pero muy influyentes a su vez. Resultan así más importantes y estables que los influenciadores de prestigios frágiles, modas volátiles, surgimientos inesperados e inestables grupos numerosos de seguidores. 


\section{Rastrear (Tracking)}

La posibilidad de reconocer la diversidad de datos e información es inagotable en la Web. Todo lo que es susceptible de ser averiguado, buscado, examinado, inspeccionado, seleccionado, reconocido, registrado, hasta mayoritariamente recuperado, lo está siendo por alguien desde algún lugar. En consecuencia, con toda esa información se generan bases de datos ilimitadas. No obstante, las mismas son fragmentarias y parciales, aunque para Kelly (2016) sólo es una cuestión de tiempo antes de lograr la integración de la información en formatos cada vez más refinados que operarán de maneras sofisticadas sobre la audiencia-usuario.

Sin embargo, desde la perspectiva de la novela distópica "1984" de George Orwell (1949, 2020), el control y la vigilancia ubicua resulta un concepto asfixiante en tanto poder ser rastreado y detectado. Desde otra mirada, Pardo Kuklinky (2016) plantea que el rastreo puede ser abordado y resuelto según el concepto de transparencia radical, en tanto tendencia más equitativa, simétrica y solidaria. Al respecto, Harari (2021) reconoce que la tendencia y la situación actual exacerbada por la pandemia, es exacta e inquietantemente inversa.

\section{Remezclar (Remixing)}

Por un lado, la disminución de los costos de equipos, programas y conectividad, junto a la reducción de la dificultad de uso para producir, facilita el desarrollo de ecosistemas de producción, tal el caso de los audiovisuales híper y multimediales primero y los transmediales luego. Han evidenciado un desarrollo tecnológico intenso según otros modos de producción y difusión (streamings, podcast, etc,) y otras alternativas desplegadas en pandemia que se transformaron en ejes vertebrales de la comunicación en las etapas de aislamiento.

Kelly (2016) presenta dos conceptos centrales vinculados a estos modos de producción. Por un lado la rebobinabilidad (rewindability) por otro la capacidad de búsqueda (findability). O sea, tanto la capacidad de volver a recuperar información innumerable veces, como la capacidad de poder buscarla, encontrarla y recuperarla. Estas dos modalidades de transformación fueron las bases para proponer nuevas formas de creación y recreación, individual o colectiva, desde donde intervenir imágenes, audios y textos en formatos multi y transmediales como indaga Scolari $(2019,2020)$.

También se propicia el advenimiento de tecnologías que facilitan la producción de prototipos rápidos y fabricación digital, habilitando desarrollo de tecnologías y prácticas inéditas. Al respecto se posiciona fuerte, encarada en el concepto de inteligencia colectiva, la Cultura del Hacedor, habilitando otros procesos de ideación, gestión, producción, circulación, consumo y validación del diseño, según Arango Sarmiento (2015). Expresa un tipo de pensamiento proyectual heterogéneo, abarcativo, múltiple y fluido. Los participantes remiten a comunidades de prosumidores activos. Para Head (2017) se facilita el acceso al conocimiento abierto, aplicaciones libres, originales modos de verificación entre 
pares, asimismo renovadas posibilidades para recrear productos con reducidas inversiones asociadas.

Sin embargo, existen ausencias legales en estos escenarios de acción. Tal el caso de los derechos de autor (copyright), condición importante para una cultura saludable, que en ocasiones ha presentado resistencias contra la innovación obstaculizando el surgimiento de nuevas alternativas productivas.

\section{Compartir (Sharing)}

Lo destacado en la economía de los entornos post-digitales es la posibilidad de repartir, distribuir y dividir la propiedad con opciones de gratuidad considerables.

Para Pardo Kuklinski (2010) la economía del compartir (sharing economy), junto a las modalidades de colaboración e intercambio a gran escala y el consumo colaborativo, reconocen antecedentes validados en experiencias similares a las realizadas analógicamente por comunidades pequeñas. Según Kelly (2016), los efectos provocados por la escala post-digital, hiperconectada y global, aportan a formalizar e incrementar hábitos de vida y consumo que remiten a comunidades inclusivas y solidarias, asimismo facilitan el acceso a los bienes por sobre la propiedad de los mismos. En contraposición, los intangibles propios de las experiencias únicas, irrepetibles e imposibles de ser copiadas, se tornan en lo realmente costoso.

\section{Incorporar conocimiento con inteligencia artificial al diseño (Cognifying)}

La inteligencia artificial potencia, provoca y acelera las disrupciones posibles en el diseño. Kelly (2016) sostiene de forma optimista, que tal accionar estimula la definición de rasgos esenciales del hombre contemporáneo y puede tender a mejorarlo, en tanto se enfoca en las transformaciones que reformulan actividades y optimizan los modos de hacerlas junto a las máquinas y robots. Tal mérito cognitivo se basa en tres innovaciones que han precipitado la llegada de la inteligencia artificial. Por un lado, la computación paralela accesible de bajo costo, entendida como la técnica de programación donde muchas instrucciones se ejecutan simultáneamente, basada en que los problemas grandes se pueden dividir en partes más pequeñas y resolverse de forma concurrente. Por otro, la Big Data (grandes datos o grandes volúmenes de datos), entendida como término evolutivo que describe cualquier cantidad voluminosa de datos estructurados, semi-estructurados y no estructurados que tienen el potencial de ser extraídos para obtener información. Finalmente, el diseño de algoritmos mejorados, entendido como conjunto ordenado de operaciones sistemáticas que permiten hallar la solución optimizada de cierto tipo de problemas. Con distintos niveles de avances potenciados por la ubicuidad y gratuidad, en tanto asignada la inteligencia arti- 
ficial a los objetos, dispositivos y aplicaciones, se supone se facilita compartir e interactuar de manera productiva y eficaz.

Para Harari (2018), los alcances son limitados y restringidos a determinadas acciones y experiencias. No hay motivo válido para suponer que la inteligencia artificial adquiera conciencia pues inteligencia y conciencia son diferentes. Mientras la inteligencia es la capacidad de plantear y resolver problemas, la conciencia es la capacidad de expresar sentimientos expresados en el sentir dolor, alegría, amor e ira, entre otros. Los hombres resuelven la mayoría de los problemas mediante los sentimientos, en tanto que las máquinas obviamente de maneras diferentes.

\section{Preguntarse (Questioning)}

Resulta contrario a la lógica, pero muy sano por cierto, que ante un nuevo descubrimiento sucedan preguntas y cuestionamientos. Se evidencia así la fragilidad inestable del conocimiento. Según Kelly (2016) se evidencian entonces nuevas ausencias de saber, que serán más profundas cuanto mayores y disruptivas sean los nuevos conocimientos generados. Entonces, la habilidad de cuestionar, plantear y formular nuevas preguntas y nuevos problemas es más desafiante que las propias respuestas, pues desencadenan nuevas indagaciones y en consecuencia nuevas soluciones.

Desde la perspectiva tradicional y estricta de la metodología de investigación se podrían formular preguntas que apelen a la conveniencia, a la trascendencia, a las implicaciones prácticas, a la utilidad metodológica, al valor teórico, entre otras variables.

Desde la perspectiva de la complejidad, siguiendo a Morín (2009), se podrían formular preguntas que posibiliten visibilizar y revelar abordajes a tejidos de eventos, acciones, interacciones, retroacciones, determinaciones y azares que configuren lo fenoménico propio de los entornos virtuales e interconectados. Preguntas que aporten a ordenar e interpretar lo intrincado, el desorden, la ambigüedad y la incertidumbre, así como estrategias temporales y fragmentarias para lograr la inteligibilidad.

Entonces, ante la magnitud de los cambios en los ecosistemas post-digitales, son también innumerables las preguntas que surgen y se disparan. Así como la necesidad de enfocar la energía y la inteligencia para descubrir, crear e innovar en consecuencia.

\section{Empezar, Recomenzar (Beginning)}

Ante el devenir histórico, en etapas de cambios profundos y fuertes como la que se transita a nivel mundial por la pandemia, trascienden los tiempos cronológicos de la inmediatez. Queda la inexorable necesidad de afrontar desafíos. Frente a esta emergencia, todos los seres humanos deben ser adaptables y cambiantes. La habilidad para afrontar los retos no es innata, se construye, se desarrolla y se perfecciona de manera tanto individual como social. 
El concepto de inevitabilidad que sostiene Kelly (2016), de manera amplia y abarcativa, contiene el acontecer de otras maneras de pensar y pensarse del hombre en los entornos reales y en los entornos post-digitales como redes contenedoras, creativas, imperfectas, abiertas y en constante mutación. Se ha verificado en los tiempos actuales de pandemia, de forma imperativa, que facilitan la generación de iniciar otros modos de estar y de ser en otros espacios y tiempos. También otros comportamientos, sujeciones y estados críticos. Los mismos se reformulan desde la simultaneidad y la emergencia de innovaciones que atraviesan los diversos ámbitos de la tecnología, de la educación, de la salud, de la política y de la economía, prioritariamente en estas circunstancias. También de la cultura, de la sociedad, del medio ambiente, entre otros. Algunos se llevan a cabo de forma institucional y comunitario, pero otros por grupos y personas aparentemente independientes integradas a ecosistemas cognitivos y culturales comunes, con capacidades de principiar, desarrollar, potenciar e hibridar experiencias paralelas.

Para Cobo (2016), una de las situaciones más complicadas de ser entendidas en los entornos post-digitales, dada su intangibilidad, es que los profundos cambios actuales exceden dispositivos, infraestructuras, plataformas, canales de intercambio e inteligencia asignada a las cosas. Más bien, residen en la necesidad de resignificación de sentido en cada inicio y reinicio que se debe construirse en comunidad.

\section{Conclusiones provisorias y discusiones}

Se ha reconocido que en entornos post-digitales acontecen prácticas relacionadas con inteligencia colectiva. Se desarrollan ecosistemas cognitivos que propician participación sustentada desde interacciones originales entre sociedad, cultura y tecnología en términos amplios. Se habilitan nuevos procesos de ideación, gestión, producción, circulación, consumo y validación del diseño. Se expresa un tipo de pensamiento proyectual heterogéneo, abarcativo, múltiple y fluido.

$\mathrm{Al}$ interior de esta tendencia, con relación a temas vinculados con las prácticas de Diseño se manifiesta una contingencia particular, desde experiencias que comparten rasgos híbridos promovidos por acciones comunes en el mundo virtual, tanto desde ambientes de educación formal como de prácticas informales y de meta-espacios intermedios.

En esta dirección se han presentado avances sobre el estado de la cuestión, con la intención de aportar a la construcción de encuadres conceptuales, identificando y examinando distintas líneas de investigación, autores y conceptos esenciales, así como posibles vacíos. Para abordar el problema se ha centrado la propuesta a partir del análisis y la presentación de una serie de tendencias formalizadas en acciones que son traducidas en competencias híbridas. Tales acciones refieren a la serie Volverse otra cosa, Devenirse (becoming); Fluir constante (flowing); Habitar pantallas (screening); Interacturar (interacting); Acceder (accesing); Filtrar (filtering); Rastrear (tracking); Remezclar (remixing); Compartir (sharing); Incorporar conocimiento con inteligencia artificial al diseño (cognifying); Preguntarse (questioning); Empezar, Recomenzar (beginning). 
Inmersos en este argumento se pueden inferir, en parte, prospectivas mediatas de los ecosistemas pedagógicos y didácticos vinculados a innovaciones digitales para aportar posteriormente a los debates sobre prácticas docentes innovadoras en entornos post-digitales. En esta dirección se ha priorizado la intención de contribuir a la producción y resignificación de conocimientos contextualizados en ambientes formales de carreras de Diseño Industrial.

Sin embargo, enfocadas en la educación, se reconoce que los cambios culturales en etapa de pandemia resisten a los usos imperativos e intensivos que ofrecen las posibilidades tecnológicas para afrontarlos y resolverlos.

Diversas prácticas son facilitadas por el acceso y uso de estas nuevas tecnologías, tales como formas sistematizadas de aprendizaje, uso del tiempo sincrónico y asincrónico, entrega de contenidos, que entre otros rasgos habilitan a la disponibilidad inmediata. Sin embargo, resulta que la presencialidad del ambiente "escuela", en sentido amplio como referente de las prácticas didácticas, es el ámbito físicos más importantes de interacciones cotidianas. Resulta el lugar donde es posible demostrar, expresar, desplegar y desarrollar vínculos interpersonales y emocionales significativos de la formación, en tanto superando sólo aspectos formativos e instruccionales. En sentido fuerte, son los ambientes de sociabilidad de la formalización del aprendizaje, de la pertenencia a la comunidad, de la expresión de los afectos.

Pareciera que la hibridación entre ambos territorios, los virtuales y los reales es el gran desafío a afrontar y resolver en el futuro inmediato. Superadas la urgencias o incorporando tales estados de vulnerabilidad y emergencia a las nuevas habitualidades, se torna fuerte la exigencia de reformular, repensar y reinventar las prospectivas mediatas de nuevos ecosistemas pedagógicos y didácticos con la intención que recuperen e hibriden lo más positivo de las experiencias remotas y presenciales.

\section{Agradecimiento}

Este estudio se encuadra en actividades del Proyecto de Investigación 15/B370 SCyTUNMdP EMIDA-CIPADI FAUD UNMdP, con dirección Diana Rodríguez Barros y codirección Gabriela Rodríguez Ciuró.

\section{Listado de Referencia Bibliográfica}

Arango Sarmiento, S. (2015). Maker Movement, una nueva cultura de invención e innovación. En youngmarketing.com v.beta. Disponible http://tinyurl.com/nlbm9vg

Bauman, Z. (2006) Vida líquida (2005). Barcelona: Paidós

- (2018). Generación líquida. Barcelona: Paidós 
Brown, T. (2016). The Next Big Thing in Design. En Design Thinking. Recuperado https:// tinyurl.com/yc4bjee5

Cobo, C. (2016). La Innovación Pendiente. Reflexiones (y Provocaciones) sobre educación, tecnología y conocimiento. Montevideo: Colección Fundación Ceibal/ Debate.

Gutierrez, A. y Freire, J. (2013). Manifiesto Crowd. Madrid: Laboratorio de Tendencias.

Kelly, K. (2016). The Inevitable: Understanding the 12 Technological Forces That Will Shape Our Future. New York: Viking Book.

Krznaric, R. (2020). Good Ancestor, The - How to Think Long Term in a Short Term World. London: Ebury Publishing Penguin Random UK.

Harari, Y. (2018). 21 lecciones para el SXXI. Debate \& Penguim Random House.

_(2021). Las lecciones del virus: lo que los grandes pensadores han aprendido de la pandemia. Yuval Harari. En El Mundo. Madrid: El Mundo. Recuperado https://tinyurl. com/4yepd56j

Head, D. (2017). Qué es la Cultura Maker y por qué queremos traerla a la educación (I). En Médium. Recuperado https://tinyurl.com/yaznzjrw

Morin, E. (2009). El pensamiento complejo. Barcelona: Editorial Gedisa.

Orwell, G. (1949, 2020). 1984. Santiago de Chile: Zig Zag.

Pardo Kuklinski, H. (2016a). Los doce verbos inevitables del postdigitalismo Parte 1. Digitalismo.com Recuperado https://tinyurl.com/cp74ta4z

_(2016b). Los doce verbos inevitables del postdigitalismo Parte 2. Digitalismo.com Recuperado https://tinyurl.com/2brz394h

_(2010). Geeknomía, un radar para producir en el postdigitalismo. Barcelona: Transmedia XXI Universidat de Barcelona.

Pardo Kuklinski, H. y Cobo, C. (2020). Expandir la universidad más allá de la enseñanza remota de emergencia. Ideas hacia un modelo híbrido post-pandemia. Barcelona: Outliers School. Barcelona. Recuperado https://tinyurl.com/4wfym $67 \mathrm{z}$

Pariser, E. (2012). The filter bubble: how the new personalized Web is changing what we read and how we think. London: Penguin Books.

Piscitelli, A. y Alonso, J. (2020). Innovación y barbarie: Seis verbos para tomar el co(mando). Barcelona: Universidat Oberta de Catalunya.

Scolari, C. (2019). Media evolution. Sobre el origen de las especies mediáticas. Buenos Aires: La Marca Editora.

_(2020. Cultura snack. Buenos Aires: La Marca Editora.

Siang, T. (2019). What is Interaction Design? En Interaction Design Foundation. Recuperado https://tinyurl.com/fvvav66h

Žižek, S. (2020). PANDEMIC!: la COVID-19 estremece al mundo. Barcelona: Anagrama. 


\begin{abstract}
In the processes of virtuality, technological changes and ubiquitous connectivity to the Internet are recognised, which influence the ways of specifying personal, social, professional and academic relationships. It is of interest to analyse central issues, by way of meta-transformations formalised in actions, which remain in force, deepening validity in the current COVID-19 pandemic scenarios. The intention is to contribute to the construction of a conceptual framework on virtuality, cognitive ecosystems, trends and behaviours in post-digital environments linked to didactic practices in project environments.
\end{abstract}

Keywords: Virtuality - Post-digital - Didactic practices - Design - Hybrid competences.

Resumo: Nos processos de virtualidade, são reconhecidas as mudanças tecnológicas e a conectividade ubíqua à Internet, que influenciam as formas de especificar as relações pessoais, sociais, profissionais e académicas. É interessante analisar questões centrais, através de meta-transformações formalizadas em acções, que permanecem em vigor aprofundando a validade nos cenários actuais da pandemia de COVID-19. Destina-se a contribuir para a construção de um quadro conceptual sobre virtualidade, ecossistemas cognitivos, tendências e comportamentos em ambientes pós-digitais ligados a práticas didácticas em ambientes de projecto.

Palavras chave: Virtualidade - Pós-digital - Práticas didácticas - Design - Competências Híbridas.

[Las traducciones de los abstracts fueron supervisadas por el autor de cada artículo] 